\title{
Assessment of Quality of Life, Family Function and Family Empowerment for Families Who Provide Home Care for a Child with Severe Motor and Intellectual Disabilities in Japan
}

\author{
Rie Wakimizu1 ${ }^{*}$, Keiko Yamaguchi'2, Hiroshi Fujioka ${ }^{3}$, Chieko Numaguchi', \\ Kaori Nishigaki, Naho Sato ${ }^{6}$, Miyuki Kishino ${ }^{7}$, Hiroshi Ozawa ${ }^{8}$, Nobuhiro Iwasaki ${ }^{9}$ \\ ${ }^{1}$ Department of Child Health Care Nursing, Division of Health Innovation and Nursing, Faculty of Medicine, \\ University of Tsukuba, Tsukuba City, Japan \\ ${ }^{2}$ Department of Nursing Science, Graduate school of Comprehensive Human Sciences, University of Tsukuba, \\ Tsukuba City, Japan \\ ${ }^{3}$ Department of Nursing, Faculty of Health Sciences, Tsukuba International University, Tsuchiura City, Japan \\ ${ }^{4}$ Department of Nursing, Faculty of Health Sciences, Ibaraki Prefectural University of Health Sciences, Ami \\ Town, Japan \\ ${ }^{5}$ Division of Nursing, Faculty of Healthcare, Tokyo Healthcare University, Shinagawa-ku, Japan \\ ${ }^{6}$ Department of Child and Family Nursing, Graduate School of Nursing, Chiba University, Chuo-ku, Japan \\ ${ }^{7}$ Al-Clinic Nakazawa, Departments by Medical Foundation Tenoukai, Hachioji City, Japan \\ ${ }^{8}$ Department of Child Neurology, Shimada Ryoiku Center Hachioji, Hachioji City, Japan \\ ${ }^{9}$ Department of Pediatrics, Ibaraki Prefectural University of Health Sciences, Ami Town, Japan \\ Email: *riewaki@md.tsukuba.ac.jp
}

Received 15 January 2016; accepted 23 February 2016; published 26 February 2016

Copyright (C) 2016 by authors and Scientific Research Publishing Inc.

This work is licensed under the Creative Commons Attribution International License (CC BY).

http://creativecommons.org/licenses/by/4.0/

\section{(c) (i) Open Access}

\section{Abstract}

Background: About 70\% of Japanese children with severe motor and intellectual disabilities (SMID) live at home, and the number is increasing. Family members have an enormous burden of daily physical care for these children. A top priority is to understand quality of life (QoL), family function, and family empowerment to effectively support these families. We aimed to assess current living situations of families with a SMID child, and to reveal the relationships between QoL, family function, and family empowerment. Methods: Sixty-five family members from $\mathbf{3 4}$ families with a SMID child participated in this study. We assessed 5 parameters using the Japanese versions

\footnotetext{
${ }^{*}$ Corresponding author.
}

How to cite this paper: Wakimizu, R., et al. (2016) Assessment of Quality of Life, Family Function and Family Empowerment for Families Who Provide Home Care for a Child with Severe Motor and Intellectual Disabilities in Japan. Health, 8, 304-317. http://dx.doi.org/10.4236/health.2016.84032 
of the following instruments: World Health Organization Quality of Life 26 (WHOQOL26), Kinder Lebensqualitats Fragebogen (KINDL), Family Assessment Device (FAD), Family Adaptability and Cohesion Evaluation Scale KG-4 (FACESKG-4), and Family Empowerment Scale (FES). Correlation and multiple regression analyses were conducted; QoL score was the objective variable. Results: Participants included 54 parents (34 mothers, 20 fathers) and 11 siblings. The mean age of SMID children was $10.4 \pm 5.03$ years. Twenty-two children needed multiple types of medical care. The mean age of parents and siblings was $41.5 \pm 6.16$ years and $15.5 \pm 2.35$ years, respectively. The mean QoL score $(3.28 \pm 0.5)$ was similar to the Japanese average. The mean KINDL score $(77.2 \pm$ 12.1) was higher than those of previous studies. The mean FAD score was $1.97 \pm 0.32$. For FACEKG-4, the score of adaptability was correlated with WHOQOL score $(r=0.459, p<0.05)$. The mean score of FES was $113.6 \pm 14$. As the result of multiple regression analysis, lower family FAD scores ( $[\mathrm{sb}]=-0.61, p<0.01)$ indicated higher family function and greater age of participants (sb $=0.495, p<0.01)$ was correlated with higher WHOQOL scores $(F=15.208, p<0.01)$. Conclusions: Our results indicated that the individual QoL depended on the age of participants (equals the years of experience caring for a SMID child) and the recognition of family function as a whole. Thus, to improve family members' QoL, we should focus on individuals and also approach the family as a whole.

\section{Keywords}

Home Care, Caregivers, Family, Japan, Quality of Life, Children with Disabilities, Severe Motor and Intellectual Disabilities

\section{Introduction}

In Japan, about 70\% of 36,650 children with severe motor and intellectual disabilities (SMID) are living at home, and the number of families who home rear children with SMID is increasing [1]-[3]. The family members, especially caregivers, experience immense stress. Studies reported that care at home is less stressful for children with SMID compared to care at other places [4]. Other studies reported disadvantages that affect the family such as chronic fatigue, worries about the future, and stress of siblings [5].

Research about the quality of life (QoL) of family members and the effects on the family system of children with SMID is limited. Needham et al. [6] focused on the adaptive behavior of individuals with mucopolysaccharidosis type II (MPS II), and the impact of MPS II on QoL of the family members and the family system. Their results from the Peds QL Family Impact Module indicated that families of patients with MPS II experienced a lower overall health-related quality of life and lower overall family functioning (including lower emotional and cognitive functioning) than those families with children who had chronic illnesses but resided in inpatient settings.

The concept of empowerment was used extensively in the field of health and social welfare from the 1980s in the United States and 1990s in the United Kingdom [7] [8]. The meaning of empowerment is summarized as follows: the families with disabilities can independently control their own lives, and the process that allows them to control their own lives. Koren et al. [9] suggested the conceptual framework of empowerment for a family rearing a child with disabilities in the community and developed the "Family Empowerment Scale" (FES).

In 1999, the concept of empowerment was presented in the Japanese guidelines (Disabled Persons' Fundamental Law), which address service and care for people with disabilities. The attitude of "family as a whole" became widely used for children with disabilities and their families and the conditions for guaranteeing their QoL have been facilitated.

Among people with disabilities, families have a role in giving medical care. This is particularly true for families with a child with SMID [10]. Miura et al. [11] reported that many children undergo tracheostomy at the age of 1 to 4 years in Japan and that family members are likely to experience anxiety, fatigue and stress.

For these families, we should focus on QoL, stress of family members, the impact on their daily lives and family empowerment. In order to improve QoL, we must understand these relationships and consider how to support the families and approach these issues. To our knowledge, there has been no research that has investigated 
the relationships between QoL, characteristics, factors of daily life (e.g., burden of care for SMID children), subjective family function, and family empowerment, for families with children who have SMID.

In this study, we investigated the relationships between QoL, subjective reports of family function, and family empowerment. We also aimed to identify interventions and clinical implications in order to, "Care for families with children who have SMID, as a whole".

The aims of this study were to assess the current living situations of family members living with a child with SMID and to clarify relationships between QoL, family function, and family empowerment.

\section{Methods}

\subsection{Participants}

Thirty-four families with a child with SMID were included in the study; 25 were nuclear families. The family members included in this study were the primary caregivers, their spouses, and siblings aged 12 years or older; however, if there was more than one sibling, the primary caregiver chose one sibling to participate and provide responses (non-mandatory).In this study, we defined a primary caregiver is the one who takes a role of home care of a child with SMID in a family members live together. The total number of participants was 65, including 54 parents (34 mothers and 20 fathers) and 11 siblings (12 - 19 years old). The mean age of the children with SMID was $10.4 \pm 5.03$ years old (range 3 - 22 years old); there were 17 girls and 16 boys. The mean age of parents was $41.5 \pm 6.16$ years old (range 30 - 61 years old).For the children with SMID, 24 had 1 - 3 siblings and 10 had no siblings. All families lived in the capital region and all of the children with SMID had a physical disability certificate with grade 1 or 2 of the Ohshima classification [12]. The diagnoses and required medical care for the children are shown in Table 1. Twenty-two needed more than one type of medical care and 12 did not require any medical care. Eight types of necessary medical care were reported by the caregivers. Suctioning was the most frequently required type of care (20 SMID children), the next was tubal feeding (16), and respiratory management (10) (Table 1). The primary caregivers were the mothers in all but one family. After home care of the SMID child was started, one mother changed places with the father and worked as the income provider while the father took care of their children at home. Ages of the primary caregivers ranged from 30 to 53 years old.

\subsection{Procedure}

All families were using the services of home visit nursing stations, pediatric welfare centers, medical care centers, day care centers or university hospital. The participants were recruited by physicians or researchers in each facility, at the time they come for regular clinical visits. Although we tried to gather the participants as many as possible, 65 families participated in this study because of limited period and institutions in three prefectures. For each family a researcher explained the details of the study to those who agreed to participate. The period of data collection was from September 2013 to August 2014.

\subsection{Measures}

The investigation consisted of: 1) attributes of the SMID child, each family member, and the whole family, 2) the primary caregiver's burden of caring for the SMID child, 3) each family member's concerns, anxieties, and needs for support, and 4) the score of each scale: QoL, family function, and family empowerment.

The attributes included diagnosis, age, gender, residential area, medical care required by the SMID child, personal distress, and distress related to caring for a child with SMID, degree of cooperation within and outside of the family and the number of family members/siblings. Next, we asked the primary caregiver and each family member to describe their perceptions of the burden of caring for the child with SMID, and their concerns, anxieties, and need for support. For assessing QoL, family function, family empowerment; we used the 5 scales described below.

The World Health Organization Quality of Life 26 (WHOQOL26) assessment was used to assess the QoL of family members over 18 years old. The World Health Organization (WHO) defines Qol as “An individuals' perception of their position in life in the context of the culture and value systems in which they live and in relation to their goals, expectations, standards and concerns". The WHOQOL Group [13] developed the WHOQOL100 and the WHOQOL26 is a shortened form of the WHOQOL100. A Japanese version of the WHOQOL26 was developed [14]. This scale is not used to assess presence or absence of disease; the purpose of 
Table 1. Subject characteristics.

\begin{tabular}{|c|c|c|}
\hline & & $(\mathrm{N}=65)$ \\
\hline & $\mathrm{n} /$ mean $\pm \mathrm{SD}$ & $\% /$ range \\
\hline Children with SMID & & $(\mathrm{n}=34)$ \\
\hline Current age & $10.4 \pm 5.03$ & $3-22$ \\
\hline Age of onset & $0.65 \pm 1.64$ & $0-8.5$ \\
\hline \multicolumn{3}{|l|}{ Gender } \\
\hline Boy & 16 & $48 \%$ \\
\hline Girl & 17 & $52 \%$ \\
\hline \multicolumn{3}{|l|}{ Diagnoses (multiple answers) } \\
\hline cerebral palsy & 9 & $20.5 \%$ \\
\hline epilepsia & 7 & $15.9 \%$ \\
\hline PVL (periventricular leukomalacia) & 5 & $11.4 \%$ \\
\hline chromosomal abnormality & 5 & $11.4 \%$ \\
\hline gene defect & 3 & $6.8 \%$ \\
\hline acute encephalipathy & 3 & $6.8 \%$ \\
\hline hypoxic ischemic encephalopathy & 3 & $6.8 \%$ \\
\hline influenza-associated encephalopathy & 2 & $4.5 \%$ \\
\hline cytomegalovirus infection & 2 & $4.5 \%$ \\
\hline pineoblastoma & 1 & $2.3 \%$ \\
\hline syringomyelia & 1 & $2.3 \%$ \\
\hline holoprosencephaly & 1 & $2.3 \%$ \\
\hline diffuse axonal injury & 1 & $2.3 \%$ \\
\hline hydrocephalus & 1 & $2.3 \%$ \\
\hline $\begin{array}{l}\text { Type of treatment given (multiple answers) } \\
\text { one or more }\end{array}$ & 22 & $64.7 \%$ \\
\hline Suctioning & 20 & $31.7 \%$ \\
\hline Tubal feeding & 16 & $25.4 \%$ \\
\hline Respiratory management & 10 & $15.9 \%$ \\
\hline Inhalation & 8 & $12.7 \%$ \\
\hline Urethral catheterization & 4 & $6.3 \%$ \\
\hline Colon irrigation & 3 & $4.8 \%$ \\
\hline CV catheter management & 1 & $1.6 \%$ \\
\hline Tracheotomy management & 1 & $1.6 \%$ \\
\hline Nothing & 12 & $35.3 \%$ \\
\hline Family caregivers & & $(\mathrm{N}=54)$ \\
\hline Age & $41.5 \pm 6.16$ & $30-61$ \\
\hline Gender & & \\
\hline
\end{tabular}


Continued

\begin{tabular}{lcc}
\hline Mother & 34 & $63.0 \%$ \\
Father & 20 & $37.0 \%$ \\
Siblings & & $(\mathrm{n}=11)$ \\
Age & $15.5 \pm 2.34$ & $12-19$ \\
Gender & & \\
$\quad$ Male & 6 & $54.5 \%$ \\
Female & 5 & $45.5 \%$
\end{tabular}

Family data

Resident area

Ibaraki

$63.1 \%$

Chiba

$9.2 \%$

Tokyo

$27.7 \%$

Personal distress

Currently

Temporarily in the past

No

$25.0 \%$

Distress about caring for SMID child

Currently

Temporarily in the past

$34.4 \%$

No

$24.6 \%$

Degree of cooperation within the family

No, not at all

$7.8 \%$

No

Moderately

$3.1 \%$

Yes

Yes, very much

$20.3 \%$

$13 \quad 20.3 \%$

$21 \quad 32.8 \%$

$23 \quad 35.9 \%$

Degree of cooperation outside the family

No, not at all

$2 \quad 3.1 \%$

No

11

$17.2 \%$

Moderately

$5 \quad 7.8 \%$

Yes

13

$20.3 \%$

Yes, very much

33

$51.6 \%$

the scale is to assess a person's subjective well-being and quality of life. The scale includes 24 items for physical health, psychological state, social relationships, environment, and 2 items for total QoL.

To assess QoL for siblings under 18 years old, we used the Kinder Lebensqualitats Fragebogen (KINDL $®$ ). It was developed in Germany, and reliability and validity have been confirmed in Japan [15]-[17]. This scale has 24 items and consists of 6 subscales; physical health, affective well-being, self-esteem, family, friends, and school. Scoring is based on a possible 100 full points. 
Family function was assessed by using the Family Assessment Device (FAD) and the Family Adaptability and Cohesion Evaluation Scale (FACES). The FAD is used to evaluate total family function [18]. It has 60 items that are divided into 7 subscales; Problem Solving (PS), Communication (CM), Role (RL), Affective Reaction (AR), Affective Intervention (AI), Behavioral Control (BC), and General Function (GF). A Japanese version of FAD was developed, and reliability and validity were confirmed by Saeki [19]. A higher score means lower family function. Furthermore, primary caregivers were asked to complete the FACESKG-IV to assess family functioning [20]. This scale includes 2 concepts for analysis: Adaptability and Cohesion. Adaptability is the ability of the family to adapt to various stressors. Cohesion is the emotional bond that family members have with each other [20]. This scale is based on equally-appearing intervals; predictable reliability was evaluated by using the coefficient of determination $\mathrm{R}^{2} 0.599$ - 0.600 [20].

Family empowerment was assessed by using the Family Empowerment Scale (FES). The FES has 34 items that utilize a 5-point Likert scale. There are 3 subscales; Family, Service System, and Social Politics [9]. The primary caregiver was asked to complete the FES. A higher score means higher family empowerment.

The primary caregivers answered all scales except KINDL. Spouses were asked to complete WHOQOL26 and FAD. Siblings were asked to complete KINDL and FAD.

\subsection{Data Analysis}

Questionnaires were included in the analysis if $90 \%$ or more of the questions were completed, and excluded if even one of our main outcomes was not completed; QoL, Family Function, or Family Empowerment. There was no one filled out a questionnaire incompletely. For clarity of descriptive contents of family members' concerns, anxieties, and needs for support, we separated the parents' responses from the siblings' responses. Content analysis [21] was conducted on the parents' data according to the following procedure. Three categories emerged from analysis of the parents' data, and meanings of subcategories for each category were determined. Meanings in each category and subcategories were checked. If there were several similar comments, we selected the most comprehensible comment to display in Table 2. We described some particular findings for the siblings' data but their data were not saturated and specific categories did not emerge.

Means, standard deviations, and response weighting were calculated for each variable for the descriptive statistics. We used Spearman rank-correlation coefficients to evaluate for continuous variables to reveal the relationships between each scale and subscales. After that, we conducted multiple linear regression analysis. By stepwise selection, we set QoL as the objective variable and 15 factors were used as the explanatory variables. For assessing family function from multiple perspectives, we used the Personal FAD scores and the Family FAD scores. Personal FAD scores measured how each family member perceived family function. Furthermore, Family FAD scores were the mean scores within the same family, which means that the scores reflected overall family functions within a single family. We excluded some explanatory variables if there was any multicollinearity.

A statistical analysis package, PASW statistics 18.0 for Mac (SPSS Japan Inc.), was used for analysis. The significance level was set at $p=0.05$.

\subsection{Ethical Considerations}

Verbal and written consent were obtained from all participants. Ethical considerations included: 1) subjects' cooperation in the survey was fully voluntary; 2) subjects were assured that refusal to participate would not result in any disadvantages or any changes to the medical care or treatment of the child; 3 ) subjects were informed that consent to cooperate could be withdrawn at any time during the study; and 4) subjects were assured that privacy would be strictly protected when the study results were published. The study was conducted with the approval of the medical ethics review board of the University of Tsukuba (No. 1004).

\section{Results}

\subsection{Primary Caregiver's Burden Caring for a Child with SMID}

Twenty-eight primary caregivers suffered from physical or mental health problems. Some had unresolved problems which were physically conspicuous, for example, pain in the wrist, knee or lower back; high blood pressure; or an irregular menstrual cycle caused by hormone imbalance. Others had problems that involved various aspects of life. There were cases where the primary caregivers had some social conflicts, for example, caring for 
Table 2. Parents' concerns, anxiety, and required support.

\begin{tabular}{|c|c|c|}
\hline Category & Sub category & Parents' \\
\hline \multirow{4}{*}{ Concern } & $\begin{array}{l}\text { SMID child's symptom } \\
\text { parents' work }\end{array}$ & $\begin{array}{l}\text { - SMID child's symptoms that might emerge with their growth and development } \\
\text { - Short life span of SMID child } \\
\text { - Unavoidable work absence and tardy caused by child's deconditioning }\end{array}$ \\
\hline & Facilities & $\begin{array}{l}\text { - Lack of facilities can take care of children with medical care } \\
\text { - Whether care staff in facilities can take care of SMID child }\end{array}$ \\
\hline & Social activity & $\begin{array}{l}\text { - Impossibility of going outside, for example absence of siblings' school event } \\
\text { - There is a member cares around an eye about SMID child, or hide him/her }\end{array}$ \\
\hline & Siblings & $\begin{array}{l}\text { - Siblings' burden with SMID child such as a hazing } \\
\text { - Impossibility of going to hospital when siblings' health becomes bad }\end{array}$ \\
\hline \multirow{5}{*}{$\begin{array}{l}\text { Anxiety about } \\
\text { future }\end{array}$} & SMID child's life & $\begin{array}{l}\text { - SMID child's livings after graduation of school } \\
\text { - No useful facilities after their parents died } \\
\text { - Transition from home rearing to take care in facility }\end{array}$ \\
\hline & Insufficient support & $\begin{array}{l}\text { - Lack of extrafamilial support } \\
\text { - Grand parents' nursing care in the future }\end{array}$ \\
\hline & Economy & - Concerns about a domestic economy \\
\hline & Parents' health & $\begin{array}{l}\text { - Health condition of caregivers } \\
\text { - Health condition of spouse keeping work hard }\end{array}$ \\
\hline & Siblings & $\begin{array}{l}\text { - Siblings' future } \\
\text { - Don't want to let siblings force take care of SMID child after parents died } \\
\text { - Not able to let siblings do what they want }\end{array}$ \\
\hline \multirow{7}{*}{$\begin{array}{l}\text { Required } \\
\text { support }\end{array}$} & Support in facilities & $\begin{array}{l}\text { - Home care services can provide hospitable care to SMID child } \\
\text { - Childcare service after school time } \\
\text { - Convenient respite care services or short stay facilities }\end{array}$ \\
\hline & Visiting service & $\begin{array}{l}\text { - Support for safe passage } \\
\text { - Person who understands SMID child and families, and can take care of them 24-hour }\end{array}$ \\
\hline & Coodination & $\begin{array}{l}\text { - Coordination with SMID child's condition and available facilities } \\
\text { - Strong connection with public service and residential community }\end{array}$ \\
\hline & $\begin{array}{l}\text { Support for caregivers } \\
\text { to do what they want }\end{array}$ & - Support for primary caregiver can work full time \\
\hline & Adviser & $\begin{array}{l}\text { - Advice for planning SMID child's future direction } \\
\text { - Adviser who know well SMID child and family's situation } \\
\text { - Support in an acute situation or disaster }\end{array}$ \\
\hline & Support for siblings & - Counseling system for siblings \\
\hline & Economical support & - Subsidy for preventing bedsore \\
\hline
\end{tabular}

and raising a child with SMID proved to be incompatible with fulltime employment. The needs of siblings were sometimes neglected, for example, the caregiver frequently missed the siblings' school events. Caregivers also experienced anxiety about their own health and physical condition.

Primary caregivers reported that there were some burdens associated with the care of the SMID child. Children with SMID can have irregular sleep patterns and caregivers reported difficulties with coping when the child's condition was bad. One mother wrote, "I have difficulty holding him in the correct position for his tubal feedings. In past few months he has not grown because he vomits when I give him tubal feeding." Caregivers also reported difficulties caused by their SMID child's growth, such as weight gain; which was particularly burdensome during bathing and increased the risk of decubitus. 


\subsection{Family Members' Concerns, Anxieties, and Needs for Support}

On the descriptive section, parents clearly and concretely wrote about various concerns, anxieties, and needs for support. Their descriptions were placed into subcategories (Table 2).

We divided descriptions of their concerns into 5 subcategories; SMID child's symptoms, parents' work, facilities, social activity, and siblings. One primary caregiver wrote the following about her child's symptoms, "I'm concerned that new symptoms might emerge as she grows and develops. Last year, she had a kidney stone and bloody urine for over 6 months. There was nothing that eased my concern about this problem.”

We divided parents' descriptions of their anxieties into 5 subcategories; SMID child's life, insufficient support, finances, parents' health, and siblings. Many parents had similar comments about their children's life, such as, "I have anxiety about her life after she graduates from the special school" and "I can’t imagine the future after she graduates from the special school."

We found 7 subcategories related to the need for support; support in facilities, visiting services, coordination, support to allow caregivers to pursue personal goals, advising, support for siblings, and financial support. Most parents wrote about the need for support in facilities, such as, "I hope that there is a facility that can provide hospitable care for my child," "I need a service that can provide care for my child after school and during long school vacations," and "I want facilities that provide convenient respite care services."

Siblings wrote less than their parents because they did not perform as much of the care for the SMID child as their parents did. But one sibling, who was 14 years old, wrote about his anxieties, "I have to choose my career with one point in mind, and that's to be able to continue caring for her (the SMID child)." Another boy, 12 years old, wrote, "After my parents die, I'm worried about whether or not we (siblings) can take care of him (the SMID child)."

\subsection{The Scores of QoL, Family Function, and Family Empowerment}

\subsubsection{The Scores of QoL Were Measured by Using WHOQOL and KINDL}

All parents and 2 siblings over 18 years old answered the WHOQOL $(n=56)$. The mean scores of each subscale are shown in Table 3. The mean of the total score was 3.28. The national average in Japan is 3.29 [14].

Siblings under 18 years old answered the KINDL $(n=9)$. The mean of the total score was 77.2. The mean scores of each subscale are shown in Table 3.

Table 3. Scores of the Japanese version of WHOQOL, KINDL, FAD, FES and FACESKG-IV.

\begin{tabular}{lcccc}
\hline & No. of items & Score range & Mean \pm SD & Range \\
\hline & & & & \\
Scores of the Japanese version of WHOQOL26 & 26 & $1.0-5.0$ & $3.28 \pm 0.5$ & $2.27-4.35$ \\
$\quad$ Physical health & 7 & $1.0-5.0$ & $3.33 \pm 0.53$ & $2.29-4.29$ \\
Psycological state & 6 & $1.0-5.0$ & $3.31 \pm 0.66$ & $1.67-4.83$ \\
Social relationship & 3 & $1.0-5.0$ & $3.39 \pm 0.5$ & $2.33-4.67$ \\
Environment & 8 & $1.0-5.0$ & $3.18 \pm 0.56$ & $2.0-4.63$ \\
2 items for total QoL & 2 & $1.0-5.0$ & $3.11 \pm 0.76$ & $1.5-5.0$ \\
& & & $7.5=9)$ \\
Scores of the Japanese version of KINDL & 24 & $20-100$ & $77.2 \pm 12.1$ & $62.5-95$ \\
Physical health & 4 & $20-100$ & $72.8 \pm 20.2$ & $35-100$ \\
Affective well-being & 4 & $20-100$ & $83.9 \pm 11.2$ & $70-100$ \\
Self-esteem & 4 & $68.9 \pm 20.6$ & $45-100$ \\
Family & 4 & $20-100$ & $83.8 \pm 12.2$ & $60-100$ \\
Friend & 4 & $20-100$ & $84.4 \pm 14.2$ & $60-100$ \\
School & 4 & $20-100$ & $70 \pm 15.8$ & $55-95$ \\
\hline
\end{tabular}


3.3.2. The Scores of Family Function Were Measured by Using the FAD and FACESKG-IV

All participants in this study answered the FAD $(n=65)$. The total mean score was 1.97 . This scale was calculated by using each subscale and the mean scores of each are shown in Table 3.

All primary caregivers answered the FACESKG-IV $(n=34)$. The total mean score of Adaptability was -1.31 \pm 2.57 , and Cohesion was $3.38 \pm 3.2$ (Table 3). Adaptability score was correlated with the WHOQOL score and it had significant negative correlation with the Family FAD score $(r=0.459, r=-0.476, p<0.05)$.

\subsubsection{The Scores of Family Empowerment Were Measured by Using the FES}

All primary caregivers answered the FES $(\mathrm{n}=34)$. The mean of the total score was 113.6. For subscales shown in Table 3; family score was 41.3, service system score was 43.2, and social politics score was 29.1.

\subsection{The Related Factors of QoL}

There were significant negative correlations between the mean WHOQOL scores and the mean Personal FAD scores and the Family FAD scores $(r=-0.576, r=-0.523, p<0.001)$. There were also significant relationships between the scores of family empowerment subscale of the FES and the score of social relationships and environment of the WHOQOL $(\mathrm{r}=0.475, \mathrm{r}=0.453, p<0.001)$.

Multiple regression analysis was performed using the score of WHOQOL as an objective variable because there were fewer KINDL scores. Table 4 shows 15 factors, such as characteristics and other possible relevant factors that were used as explanatory variables. Lower Family FAD scores (standard partial regression coefficient $[\mathrm{sb}]=-0.61, p<0.01)$ and greater age of participants $(\mathrm{sb}=0.495, p<0.01)$ were correlated with higher WHOQOL scores $(\mathrm{F}=15.208, p<0.01)$ as shown in Table 4.

\section{Table 4. Factors related to WHOQOL of family members with SMID child $(\mathrm{N}=56)$.}

\begin{tabular}{|c|c|c|c|}
\hline & & $\mathrm{sb}$ & $p$-value \\
\hline Age of SMID child & & 0.122 & 0.47 \\
\hline Age of participant & & 0.495 & $<0.01^{* *}$ \\
\hline Status of medical care & Yes/No ${ }^{\#}$ & 0.22 & 0.10 \\
\hline Resident area & 1: Ibaraki, 2: Chiba, 3: Tokyo & 0.252 & 0.07 \\
\hline Gender & 1: Female, 2: Male & -0.049 & 0.74 \\
\hline Number of brothers & & 0.075 & 0.60 \\
\hline Personal distress & 1: No, not at all, 2: Temporarily, 3: Currently & -0.17 & 0.24 \\
\hline Distress about caring for SMID child & 1: No, not at all, 2: Temporarily, 3: Currently & -0.004 & 0.98 \\
\hline Degree of cooperation within the family & $\begin{array}{c}\text { 1: No, not at all, 2: No, 3: Moderately, } \\
\text { 4: Yes, 5: Yes, very much }\end{array}$ & 0.026 & 0.873 \\
\hline Degree of cooperation outside the family & $\begin{array}{c}\text { 1: No, not at all, 2: No, 3: Moderately, } \\
\text { 4: Yes, 5: Yes, very much }\end{array}$ & 0.102 & 0.511 \\
\hline Personal FAD score & & 0.135 & 0.668 \\
\hline Family FAD score & & -0.61 & $<0.01^{* *}$ \\
\hline FES score ${ }^{\S}$ & & -0.224 & 0.17 \\
\hline FACESKG-IV adaptability ${ }^{\S}$ & & 0.267 & 0.08 \\
\hline FACESKG-IV cohesion $^{\S}$ & & -0.179 & 0.25 \\
\hline $\mathrm{R}^{2}$ & & 0.549 & \\
\hline adjusted $\mathrm{R}^{2}$ & & 0.513 & \\
\hline
\end{tabular}

sb: the values are standardized partial regression coefficients. ${ }^{*}: p<0.05,{ }^{* *}: p<0.01$; ${ }^{*}:$ reference category; ${ }^{\uparrow}:$ Family FAD score was the mean score within the same family; ${ }^{\S}$ : Primary caregivers’ FES and FACESKG-IV scores were applied for their family members. 


\section{Discussion}

Over $80 \%$ of the primary caregivers suffered from physical or mental health problems, and they reported that the burdens associated with the care of their child with SMID. We extracted 5 subcategories of concerns, 5 of anxieties, and 7 of need for support in their daily life. Siblings wrote these descriptions less than their parents, however some of them reported their future anxiety such as caring a child with SMID after their parents died. Our new finding was that the higher age and the higher family function contribute better QoL of primary caregivers and their spouses.

\subsection{Living Conditions of Families with Children with SMID}

In Japan, 60\% of families are considered nuclear families [22]. In our study of families with children with SMID, there were 25 nuclear families and 9 extended families for a total of 34 families. We had predicted that the proportion of extended families would account for a substantial number in our study because the care burden of a child with SMID is enormous for a nuclear family.

Twenty-two children with SMID in our study needed more than one type of medical care. There were 8 different types of care that were needed; suctioning, tubal feeding, and respiratory management were the most frequent types. Previous research found that providing medical care is physically and psychologically taxing for primary caregivers [5]. In the current study, we revealed that over $80 \%$ of primary caregivers suffered from physical and mental health problems such as pain in joints (e.g., wrist, knee, and lower back), high blood pressure, and irregular menstrual cycle caused by hormone imbalance. Caregivers reported dealing with irregular sleep patterns of SMID children, periodic episodes of bad conditions for children, and weight gain of children that created problems with bathing and increased the risk of decubitus. Nurses and other medical care staff should understand these problems and be prepared to offer assistance.

For various problems in life, we found that social circumstances created conflicts for some families. For example, caring for and raising a child with SMID was incompatible with work schedules. Caregivers also frequently missed siblings' school events. We must assess the problems that disrupt family life and implement appropriate interventions, such as linking families to local support services.

The present study showed that the family members' concerns were divided into 5 subcategories, anxieties into 5 subcategories, and needs for support into 7 subcategories. In comparing the literature to the actual living situations of families caring for children with SMID at home [23], similar results were found. There were daily life issues such as "caregiver exhaustion," "psychological problems of siblings," "insufficient service systems and difficulties with use of services," "social isolation (intra/extra)," and "fear of not being able to continue child rearing.” For families who decide to continue rearing their children with SMID at home, our results indicate that the establishment of new service systems and the promotion of family empowerment are absolutely essential. Comprehensive assessment and support for families with children with SMID are also important.

\subsection{The Scores of QoL, Family Function, and Family Empowerment}

The mean score of WHOQOL was lower than the national average for Japanese people [14]. The mean scores of physical health and psychological state were also lower than the national average. On the other hand, the mean scores of social relationships and environment were both higher than the national averages. We suspect that these results could be related to the enormous burden of caring for children with SMID. In particular, partial sleep deprivation is stressful for caregivers. In order to reduce these burdens or compensate for the negative effects of these issues, parents may develop closer social relationships (e.g., mothers share some information by using social networking or special school, etc.), and adapt their surroundings to get help from others (e.g., utilization of home visit nursing care and negotiation with helpers or personnel of their local welfare division). This type of positive adaptive behavior could explain the higher mean scores of social relationships and environment of their QoL scores. In addition, the families with children with SMID may develop closer relationships with social service agencies and other supportive social environments that start from the birth of their children. Parents may tend to seek social solutions when they encounter problems related to their child's health or welfare. This may have contributed to the higher mean scores of social relationships and environment. In Japan, even healthy infants receive constructive intervention, such as routine health examinations. Children with SMID (0.06\% of the population), among others, receive additional interventions. 
This was the first study that used KINDL to investigate the QoL of siblings of children with SMID in Japan. The mean KINDL scores of junior high school students (ages from 13 to 15 years old) in previous studies was 60.9 among healthy children [16], 71.8 for children who had cancer [24], and 60.3 to 66.6 for children who had asthma [25]. Compared with these mean scores, the QoL scores of siblings of children with SMID were higher. We hypothesize that parents are more likely to encourage siblings to get physically involved in the care of the children with SMID, compared to families with children with other developmental disabilities. Furthermore, siblings have "a place of my own" within the family because children with SMID have less spontaneous involvement compared to children with other disabilities. The siblings' responses suggest that siblings recognized their own role in the family, for example, "I am a necessary person in my family," which would contribute to self-esteem. Siblings showed an ability to evaluate their personal physical health conditions; but their estimates may have been higher because of familiarity with the SMID child's condition. Data from interviews suggests that siblings have good communication and emotional engagement with the family. For these reasons, siblings regarded their QoL as being higher. In our study there were only 9 siblings under 18 years old, so research with larger samples should be conducted in the future.

Participants in the present study had lower scores for 5 subscales of FAD; PS, RL, AR, AI, BC, compared with the scores reported by Saeki [19]. A lower score means higher family function; thus the 5 subscale scores indicated that family functions were better among families with children who have SMID. Among previous studies that used FAD, there is no study that targeted families with children with SMID. Family functions in this study were higher than previous studies. These findings may be related to the characteristics of the children with SMID and the developmental stage of the family. Even after children with SMID reach puberty, for better or worse, their families must perform the initial developmental task of the family which is to take care of and rear the children. So cohesiveness, recognition of roles, and open communication would help to maintain a high level of family function. Epstein [18] suggested that individual aspects of family function cannot be separated from each other, and that one function influences other functions. Therefore we should support the families with children who have SMID by promoting their strengths, so that total family function will be improved.

From the results of the FACESKG-IV, the scores of Adaptability were significantly correlated with the WHOQOL scores and the Family FAD scores. It appeared that individuals, who reported adaptability of family, also recognize that their QoL and family function were high. Recently, the concept of adaptability has gathered attention as the outcome of parenting and family intervention [26]. We advocate that adaptability should be assessed when we observe, intervene, and support individual family members and the family as a whole.

With regards to family empowerment, FES scores in Japan were significantly lower than those of previous studies conducted overseas [9] [27] [28]. In this study of families with children with SMID, all scores of FES subscales were higher than those of the previous studies conducted with families rearing children with developmental disorders in Japan [27] [29] [30].

As described above, family empowerment was high as observed in the subscale scores. Potential reasons for these findings could be related to the interfamilial relationships that were enhanced because of the needs of the child with SMID. Stronger bonds could be formed as the family works together to provide physical care for the SMID child. Higher family empowerment may be interpreted as stronger affective bonds within the family. This is demonstrated more clearly when we compare the families with children with SMID to families with children who have developmental disabilities.

Furthermore there was a significantly weak correlation between "family" of the FES and the psychological state of the WHOQOL $(r=0.373, p<0.05)$. Having a greater sense of control and competence in their ability to assess and manage the SMID child's condition and problems of daily life may contribute to higher levels of family empowerment. "Service system" scores of FES were high because families with a child with SMID needed to develop close social relationships in order to continue life at home. Also "social politics" scores of FES were high. This score might be high because families had no choice but to cooperate with the city welfare division and to depend on the benefits package.

\subsection{The Related Factors of QoL}

From the findings of multiple regression analysis, QoL scores of participants were significantly correlated with participants' age and family FAD scores.

The older the age of participants and the higher QoL scores meant increased confidence and increased expe- 
rience in managing the condition of the SMID child. For our participants, the extra confidence and experience probably contributed to feelings of control over life and circumstances. This consideration is supported by the facts that: $76 \%$ of children with SMID have congenital disabilities that manifest within one year after birth; at the time of the data collection, the mean age of the children was $10.4 \pm 5.03$ years old; and in the early phase of caring for a child with SMID, the family would typically struggle with different needs and would have difficulties making decisions about the child's condition.

It is very interesting that families in our study had higher family function as a whole and higher individual scores for QoL. On the one hand, it is easy to understand the hypothesis that there would be a correlation between individual QoL scores and individual recognition of family function. On the other hand, our findings indicated that family function as a whole, contributed to individual QoL, but not the individual family functions. In other words, the individual QoL depended on the recognition that the family functions as a whole, and this also includes oneself. If only one family member regarded their family function as high, his/her QoL would not increase. All family members needed to recognize that the family was functioning effectively and then individual QoL showed improvement. The current study revealed that in order to improve family members' QoL, we should not only focus on the individuals, but view the family as a whole. It is substantially important to know how each family member evaluates the family function as a whole.

\subsection{For the Clinical Practice}

Medical professionals should understand that caregivers tend to take burdens of care of their child with SMID in the family, and they had some problems physically or mentally. To reduce these burdens or resolve these problems, we should provide information about the support system of home medical care at each residential area, link them to utilization of home visit nursing care or bathing assistance service. Not only caregivers also siblings need to have a chance that they share their concerns and anxieties with others families of a child with SMID for example in a parent's support group. In order to improve QoL of caregivers we need to regard their family function and consider effective intervention at each family.

\subsection{The Limitation of This Study}

In this study the number of the participants was relatively small. Our participants were recruited by physicians and included only those who made regular visits to the hospitals for the SMID child. Therefore, it is possible that children with SMID and caregivers who did not visit a physician during the recruitment period and/or who did not share a trusting relationship with their physician (e.g., physician found it awkward to seek participation) were excluded from the participant group. While caution is required for generalizing the findings of this research, our results suggest that assessing family function and supporting family empowerment are necessary when assisting families with children with SMID.

\section{Conclusion}

Primary caregivers reported the burdens associated with the care of the SMID child and difficulties caused by their SMID child's growth. Siblings reported the anxiety of their future related with a child with SMID thought the number of data that they provided were less in this study. This report from siblings remains a matter of research for improving their QoL. And in our results of multiple regression analysis, QoL scores of parents were significantly correlated with participants' age and family FAD scores. Therefore QoL of parents is affected by their age, equals the years of experience caring for a SMID child and the recognition of family function as a whole. Thus, to improve family members' QoL, medical professionals should offer assistance and link them to local support services for reduction of their burden by aging. In addition, we should approach the family as a whole focusing family function per family unit.

\section{Disclosure}

The authors declare that they have no competing interests.

\section{Acknowledgements}

This study was funded by the Ministry of Education, Culture, Sports, Science and Technology, Japan (Grant-in- 
Aid for Challenging Exploratory Research, 2015-2017).

\section{References}

[1] Nasato, H. (2011) The Life and Rights of People with Severe Motor and Intellectual Disabilities-Focused on Those Who Had Prolonged Admissions. Pediatric Nursing, 34, 547-552. (In Japanese)

[2] Okada, K. (2001) The History of Severe Motor and Intellectual Disabilities. Pediatric Nursing, 24, 1082-1089. (In Japanese)

[3] Ozawa, H., Kato, I., Ozaki, H., Ishizuka, T., Arimoto, K. and Kimiya, S. (2007) The Present Situation of Children with Psycho-Motor Disabilities and Their Parents. No to Hattatsu, 39, 279-282.

[4] Hasegawa, M. (2010) Building a Cognitive Model for Mothers of Children with Severe Motor and Intellectual Disabilities to Allow the Whole Family to Live at Home. Journal of Severe Motor and Intellectual Disabilities, 35, 371-376. (In Japanese)

[5] Yamaguchi, S., Takataya, K. and Ogiwara, T. (2005) Study of Mental Health and Its Related Factors Including Burden on Caregivers of Children/Persons with Severe Motor and Intellectual Disabilities. Yamanashi Nursing Journal, 4, 4148. (In Japanese)

[6] Needham, M., Packman, W., Rappoport, M., Quinn, N., Cordova, M. and Macias, C. (2014) MPS II: Adaptive Behavior of Patients and Impact on the Family System. Journal of Genetic Counseling, 23, 330-338. http://dx.doi.org/10.1007/s10897-013-9665-4

[7] Oda, K., Kuda, N. and Sugimoto, T. (1999) The Theory and Technique of Practice of Empowerment. Chuohoki Publishing CO, Tokyo. (In Japanese)

[8] Ogawa, Y. (1998) The Empowerment of Disabled People-Welfare of Persons with Disabilities in the United Kingdom. Akashi Shoten, Tokyo, 167-168. (In Japanese)

[9] Koren, P.E., DeChillo, N. and Friesen, B.J. (1992) Measuring Empowerment in Families Whose Children Have Emotional Disabilities: A Brief Questionnaire. Rehabilitation Psychology, 37, 305-321. http://dx.doi.org/10.1037/h0079106

[10] Ogura, K., Asami, S., Fumiko, H. and Hayama, K. (2012) Storytelling of Mothers about Decision Making to Introduce Medical Care at Home for Persons with Severe Motor and Intellectual Disabilities. Bulletin of School of Nursing Saitama Medical University, 5, 23-30. (In Japanese)

[11] Miura, K., Suzuki, Y., Kumagai, T., Hayakawa, C., Matsumoto, A. and Miyazaki, S. (2005) Tracheostomy for Home Care Patients with Severe Motor and Intellectual Disabilities. No to Hattatsu, 37, 293-298. (In Japanese)

[12] Okada, K., Suemitsu, S., Suzuki, Y., Suemitsu, S. and Egusa, Y. (2005) Manual of Treatment and Education of Children with Severe Motor and Intellectual Disabilities. 2nd Edition, Ishiyaku syuppan, Tokyo. (In Japanese)

[13] World Health Organization Group (1993) Study Protocol for the World Health Organization Project to Develop a Quality of Life Assessment Instrument (WHOQOL). Quality of Life Research, 2, 153-159. http://dx.doi.org/10.1007/BF00435734

[14] Tasaki, M. and Nakane, Y. (2007) WHOQOL26 Manual Improved Edition. Kaneko shobou, Tokyo. (In Japanese)

[15] Ravens-Sieberer, U., Gortler, E. and Bullinger, M. (2000) Subjective Health and Health Behavior of Children and Adolescents-A Survey of Humburg Students within the Scope of School Medical Examination. Gesundheitswesen, 62, 148-155. http://dx.doi.org/10.1055/s-2000-10487

[16] Shibata, R., Nemoto, Y., Matsuzaki, K., Tanaka, D., Kawaguchi, T. and Kanda, A. (2003) A Study of Kid-KINDL Questionnaire for Measuring Quality of Life in Elementary School Children in Japan. Journal of the Japan Pediatric Society, 107, 1514-1520. (In Japanese)

[17] Watanabe, S., Furusyo, J., Sato, H., Nemoto, Y., Shibata, R. and Matsuzaki, K. (2005) Building a Counseling System Model for the Mental Problems of Adolescents in School for the National Plan of the Early 21st Century for the Health of Mothers and Children. Health and Labor Science Research Grant Paper. http://www.aiiku.or.jp/ doc/houkoku/h16/65332010.pdf

[18] Epstein, N.B., Baldwin, L.M. and Bishop, D.S. (1983) The McMaster Family Assessment Device. Journal of Material and Family Therapy, 9, 171-180. http://dx.doi.org/10.1111/j.1752-0606.1983.tb01497.x

[19] Saeki, T., Asukai, N., Miyake, Y., Miguchi, M. and Yamawaki, S. (1997) The Reliability and Validity of Family Assessment Device (FAD) Japanese Version. Archives of Psychiatric Diagnostic and Clinical Evaluation, 8, 181-192. (In Japanese)

[20] Tatsuki, S. (1999) The Theoretical and Empirical Validation of Family System-Consideration of Validity of the Circumplex Model of Marital and Family System by Olson. Kawashima Shoten, Tokyo, 188-207. (In Japanese)

[21] Berelson, B. (1952) Content Analysis in Communication Research. Glencore, Ill. Free Press. Inaba M. Content Analysis, Misuzu syobou, Tokyo. (In Japanese) 
[22] Japan Ministry of Health, Labor and Welfare (2011) Comprehensive Survey of Living Conditions. Household Statistics Office of Vital, Health and Social Statistics Division, Statistics and Information Department. Tokyo. (In Japanese)

[23] Fujioka, H., Wakimizu, R., Yamaguchi, K., Sato, N., Nishigaki, K. and Numaguchi, C. (2014) The Actual Situation of Families Rearing Children with Severe Motor and Intellectual Disabilities at Home: A Literature Review. Journal of Child Health, 73, 599-607. (In Japanese)

[24] Hiraga, N., Furuya, K., Koike, H. and Wakimizu, R. (2013) Assessment of Quality of Life for Children with Cancer: An Analysis of Self-Assessment and Proxy-Assessment. Journal of Japanese Society of Pediatric Oncology Nursing, 8, 7-16. (In Japanese)

[25] Nemoto, Y., Matsuzaki, K., Shibata, R., Furusyo, J., Sone, M. and Sato, H. (2005) Consideration of the Difference of Cognition between Children and Their Mothers by Using QOL Questionnaire Elementary Student Version. Psychiatria et Neurologia Peadiatrrica Japonica, 45, 159-165. (In Japanese)

[26] Sanders, M.R., Morawska, A., Haslam, D.M., Filus, A. and Fletcher, R. (2014) Parenting and Family Adjustment Scales (PAFAS): Validation of Brief Parent-Report Measure for Use in Assessment of Parenting Skills and Family Relationships. Child Psychiatry \& Human Development, 45, 255-272. http://dx.doi.org/10.1007/s10578-013-0397-3

[27] Wakimizu, R., Fujioka, H., Furuya, K., Miyamoto, S., Iejima, A. and Yoneyama, A. (2011) Development of Family Empowerment Scale Japanese Version for Measuring the Empowerment of Families Rearing a Child with Disability. Journal of Health and Welfare Statistics, 57, 33-41. (In Japanese)

[28] Dempsey, I. and Dunst, C.J. (2004) Help-Giving Styles as a Function of Parent Empowerment in Families with a Young Child with a Disability. Journal of Intellectual and Developmental Disability, 29, 50-61. http://dx.doi.org/10.1080/13668250410001662874

[29] Wakimizu, R. (2012) Actual Situation Survey of Empowerment of Families Rearing a Child with DisabilitiesComparative Discussion with Two Different Groups, Severe Motor and Intellectual Disabilities and Developmental Disabilities. Journal of Ambulatory and General Pediatrics, 15, 25-30. (In Japanese)

[30] Ando, M., Iemura, A., Nakamura, R., Shibata, Y. and Wakimizu, R. (2014) Relationships between Parenting Style, Children's Tendency for Problem Behavior, Mental Health, and Family Empowerment of Parents Who Received Counseling about Children's Development. International Nursing Care Research, 13, 35-43. (In Japanese) 